\title{
The D-amino acid peptide D3 reduces amyloid fibril boosted HIV-1 infectivity
}

\author{
Marek Widera', Antonia Nicole Klein², Yeliz Cinar ${ }^{2}$, Susanne Aileen Funke ${ }^{2,4^{*}}$, Dieter Willbold ${ }^{2,3,5^{*}}$ \\ and Heiner Schaal ${ }^{1,5^{*}}$
}

\begin{abstract}
Background: Amyloid fibrils such as Semen-Derived Enhancer of Viral Infection (SEVI) or amyloid- $\beta$-peptide (A $\beta$ ) enhance HIV-1 attachment and entry. Inhibitors destroying or converting those fibrils into non-amyloidogenic aggregates effectively reduce viral infectivity. Thus, they seem to be suitable as therapeutic drugs expanding the current HIV-intervening repertoire of antiretroviral compounds.

Findings: In this study, we demonstrate that the small D-amino acid peptide D3, which was investigated for therapeutic studies on Alzheimer's disease (AD), significantly reduces both SEVI and A $\beta$ fibril boosted infectivity of HIV-1.

Conclusions: Since amyloids could play an important role in the progression of AIDS dementia complex (ADC), the treatment of HIV-1 infected individuals with D3, that inhibits $A \beta$ fibril formation and converts preformed $A \beta$ fibrils into non-amyloidogenic and non-fibrillar aggregates, may reduce the vulnerability of the central nervous system of HIV patients for HIV associated neurological disorders.
\end{abstract}

Keywords: HIV-1 infection, SEVI, D3, Amyloid-beta, Alzheimer's disease, D-enantiomeric peptide, Drugs, Monomers, Oligomers

\section{Findings}

Amyloid fibrils exhibiting a cationic surface [1], for example those of the Alzheimer's disease (AD) related amyloid- $\beta$ peptide $(A \beta)$ and the Semen derived Enhancer of Viral Infection (SEVI), promote HIV infection by facilitating viral attachment through neutralization of the electrostatic repulsion between the negatively charged surface of virions and target cells [2-4]. Experimental approaches to reduce SEVI-mediated enhancement of HIV1 infection by amyloid binding agents have already been described [5-9]. However, except for epigallocatechin-3gallate, the major active constituent of green tea, most of these compounds were shown to bind, but not to eliminate amyloids. Recently, it was demonstrated that the small D-amino acid peptide D3 converts A $\beta$ oligomers and fibrils into non-amyloidogenic, non-fibrillar and

\footnotetext{
* Correspondence: aileen.funke@hs-coburg.de; D.Willbold@fz-juelich.de; schaal@uni-duesseldorf.de

${ }^{2}$ Forschungszentrum Jülich, ICS-6, 52425 Jülich, Germany

'Institut für Virologie, Heinrich-Heine-Universität, D-40225 Düsseldorf,

Germany

Full list of author information is available at the end of the article
}

non-toxic aggregates and reduces the cognitive deficits of the central nervous system in transgenic AD model mice [10]. Because many amyloid fibrils, despite their composition of different peptides or proteins, show significant structural similarities like a typical cross-beta sheet quaternary structure, we intended to analyze the inhibitory capacity of D3 to reduce other amyloid caused pathologic effects.

In order to utilize amyloidogenic inhibitors to reduce fibril boosted viral infectivity, we firstly wanted to unravel whether fibrils or even monomers or oligomers of $\mathrm{A} \beta$ are the causative agents for the infectivity enhancing effect. To achieve this, synthetic human $A \beta(1-42)$ peptide (purity $>95 \%$ ) was purchased from Bachem (Bubendorf, Switzerland). Lyophilizated $A \beta(1-42)$ was dissolved to $1 \mathrm{mM}$ with hexafluoroisopropanol (HFIP) overnight at room temperature (RT). Prior to use, HFIP was evaporated using a SpeedVac Concentrator 5301 (Eppendorf; Hamburg, Germany) at RT. For preparation of $A \beta(1-42)$ fibrils, the $A \beta$ pellet was dissolved in PBS (phosphate buffered saline: $140 \mathrm{mM} \mathrm{NaCl}, 2.7 \mathrm{mM} \mathrm{KCl}, 10 \mathrm{mM}$ $\mathrm{Na}_{2} \mathrm{HPO}_{4}$, and $1.8 \mathrm{mM} \mathrm{KH} \mathrm{PO}_{4}, \mathrm{pH}$ 7.4) to $1 \mathrm{mM}$
C Biomed Central

(c) 2014 Widera et al.; licensee BioMed Central Ltd. This is an open access article distributed under the terms of the Creative Commons Attribution License (http://creativecommons.org/licenses/by/2.0), which permits unrestricted use, distribution, and reproduction in any medium, provided the original work is properly cited. 
and incubated four days at $37^{\circ} \mathrm{C}$ without shaking. To remove all soluble $A \beta$, the samples were washed by centrifugation and redissolved in PBS. For preparation of $A \beta(1-42)$ mono- and oligomers, the $A \beta$ pellet was dissolved in SEC buffer (size exclusion chromatography

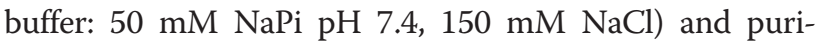
fied using size exclusion chromatography (Figure 1D). To test the different $A \beta$ conformers for their infectivity
A

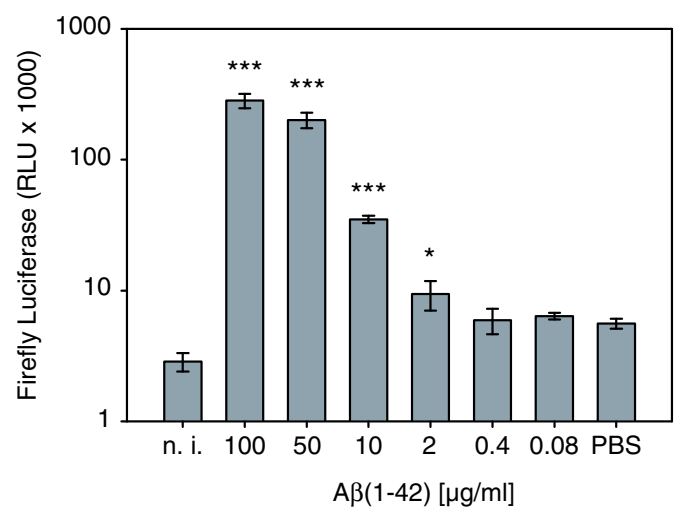

C

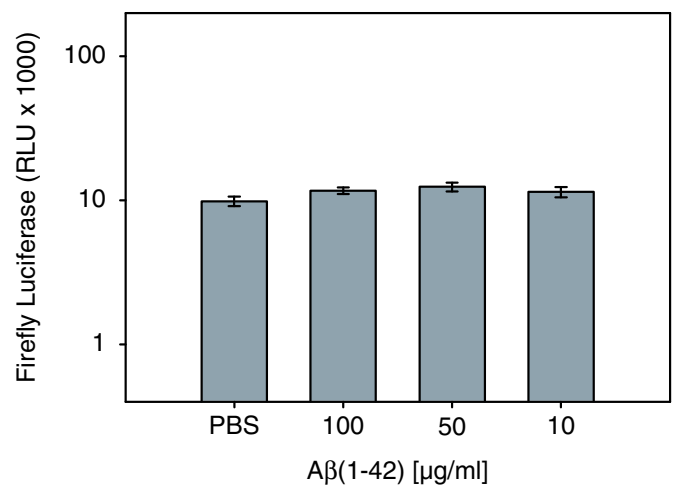

$\mathbf{E}$

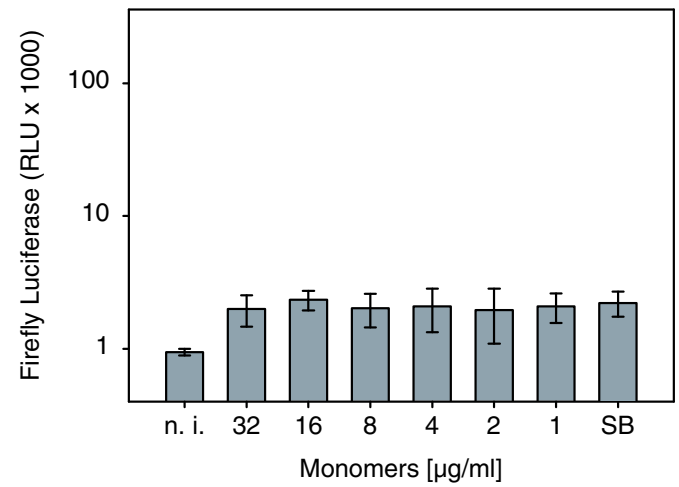

B
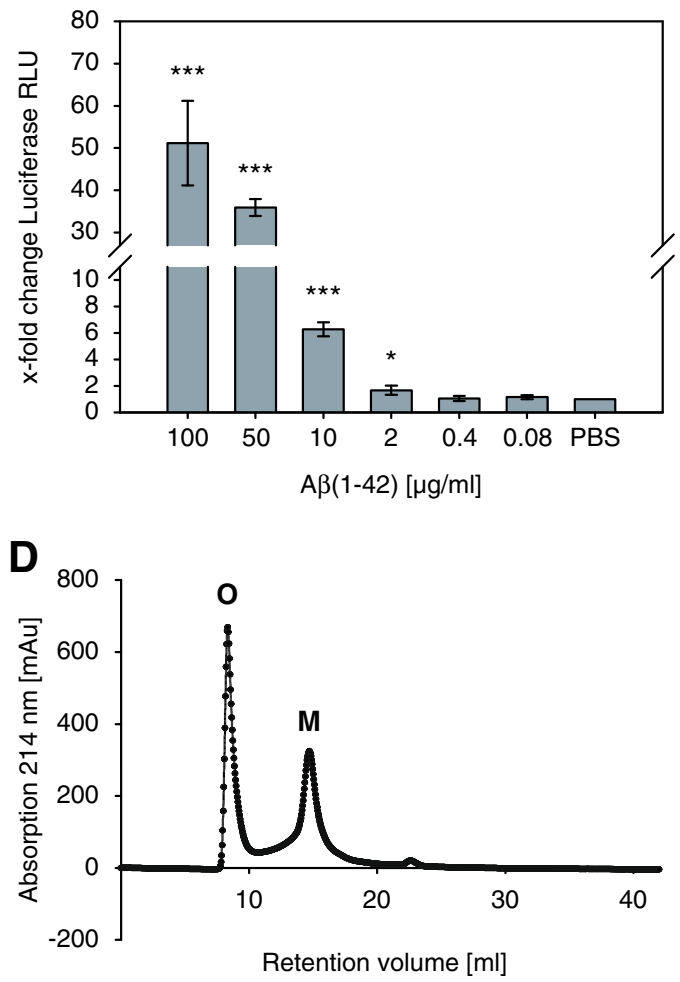

$\mathbf{F}$

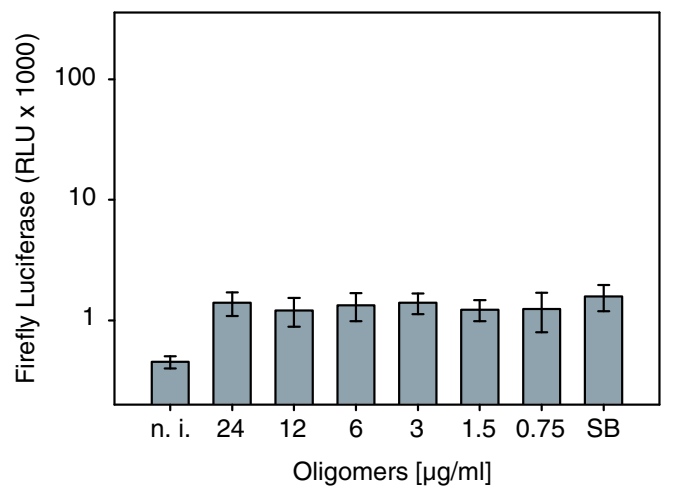

Figure $1 \mathbf{A} \boldsymbol{\beta}(\mathbf{1 - 4 2})$ fibrils but not mono- and oligomers enhance HIV-1 infection of TZM-bl cells. (A) Equal amounts (500 TCID 50 as determined with TZM-bl cells using supernatant of transfected HEK 293T cells) of the dual-tropic HIV-1 lab strain NL4-3 PI 952 [11] were pre-incubated for 5 min at RT with $A \beta(1-42)$ fibrils. Subsequently, the pretreated viruses were used to infect TZM-bl reporter cells and infectioninduced luciferase activity was assayed $48 \mathrm{~h}$ post infection. ( ${ }^{* * *} \mathrm{p}<0.001,{ }^{*} \mathrm{p}<0.05$ referred to PBS treated and infected cells). (B) X-fold change of luciferase enhancement was quantified relative to cells infected in the absence of AB(1-42) fibrils (PBS). (C) Luciferase RLUs of non-infected cells, which were treated with the indicated concentrations of $A \beta(1-42)$. (D) Chromatogram of a size exclusion chromatography (SEC) showing the absorption profile of $A \beta(1-42)$ monomers $(M)$ and oligomers $(O)$, which were used in the following analysis. (E and F) The same experiments as in (A) but viruses were pre-incubated with Aß(1-42) mono- and oligomers obtained by SEC shown in (D). milli-absorbance-units (mAu); noninfected (n.i.); relative light units (RLU); size exclusion chromatography buffer (SB). 
enhancement potential, we used TZM-bl reporter cells that harbor a luciferase and a $\beta$-galactosidase expression cassette under the control of the HIV-1 LTR promoter, which are activated in infected cells due to expression of the HIV-1 trans-activator of transcription (Tat). These reporter cells were infected with equal amounts of the dual-tropic (R4 and R5) HIV-1 PI 952 [11] either in presence or absence of $A \beta(1-42)$ monomers, oligomers or fibrils. For luciferase measurements, cells were rinsed in PBS and dispensed in passive lysis buffer (PLB) and shaken for $15 \mathrm{~min}$ at RT. Luciferase activity of cell lysates was measured by adding Beetle-Juice (p.j.k; Kleinblittersdorf, Germany) using an Infinite 200 PRO multimode reader (Tecan; Männedorf, Switzerland). We observed that $A \beta(1-42)$ fibrils (Figure $1 \mathrm{~A}$ and $\mathrm{B}$ ) but not mono- or oligomers (Figure $1 \mathrm{E}$ and $\mathrm{F}$ ) were able to enhance HIV-1 infection of TZM-bl cells. The enhancing effect of $A \beta(1-42)$ fibrils on HIV-1 infectivity was observed at a concentration of $2 \mu \mathrm{g} / \mathrm{ml}$ and augments with increasing $A \beta(1-42)$ fibril concentrations, whereas $A \beta(1-42)$ fibrils alone had no effect on luciferase expression of TZM-bl cells (Figure 1C). In agreement with Münch et al. [3], but in contrast to Wojtowicz et al. [2], we did not observe any enhancing effect on HIV-1 infection when using $A \beta(1-40)$ fibrils (Innovagen; Lund, Sweden) irrespective of whether these were incubated for four or six days of oligomerization under the same conditions as described above (Figure 2). The reason for this discrepancy was already discussed by Münch et al. arguing that amyloid fibrils composed of the same protein can show different conformations with distinct phenotypes [12].
To analyze whether the infectivity boosting effect of $\mathrm{A} \beta(1-42)$ but not $\mathrm{A} \beta(1-40)$ fibrils was cell type specific, we applied our approach also to the HIV-1 susceptible Molt-4 T cells [13,14]. Equal amounts of an R4 tropic HIV-1 NL4-3 derivate, which expresses a NEF-GFP fusion protein, were pre-incubated for $5 \mathrm{~min}$ at RT with $A \beta(1-42)$ or $A \beta(1-40)$ fibrils $(10 \mu \mathrm{g} / \mathrm{ml})$ and PBS as a control, respectively. Subsequently, the pre-treated viruses were used to infect Molt-4 T cells and the percentage of infected (GFP positive) cells was assayed by FACS analysis by using FACSCalibur (BD; Franklin Lakes, USA) $48 \mathrm{~h}$ post infection. As expected, treatment with $\mathrm{A} \beta(1-42)$ but not with $\mathrm{A} \beta(1-40)$ fibrils resulted in $\sim$ sixfold higher percentage of GFP positive $T$ cells when compared to PBS treated cells indicating that $A \beta(1-42)$ specifically enhances viral infectivity also in $\mathrm{T}$ cells (Figure 3).

We further addressed the question of whether the boosted viral infectivity was also dependent on the membrane fusion activity of the gp41 N-terminus. Therefore, we transfected HEK 293T cells with pNL4-3 or the protease cleavage site mutant pNL Prot.Xa that prevents the Env glycoprotein mediated membrane fusion (kindly provided by Valerie Bosch) and performed immunoblot analysis of cellular as well as virion associated gp160/gp41 by using Chessie 8 antibody [15]. Virions were pelleted by using sucrose centrifugation as described before [16]. Next, we incubated TZM-bl cells with wildtype and mutant virus. By adding $A \beta(1-42)$ fibrils, the defect in viral entry could not be restored indicating that the fibril-mediated enhancement was also dependent on the membrane fusion activity of gp41 (Figure 4).

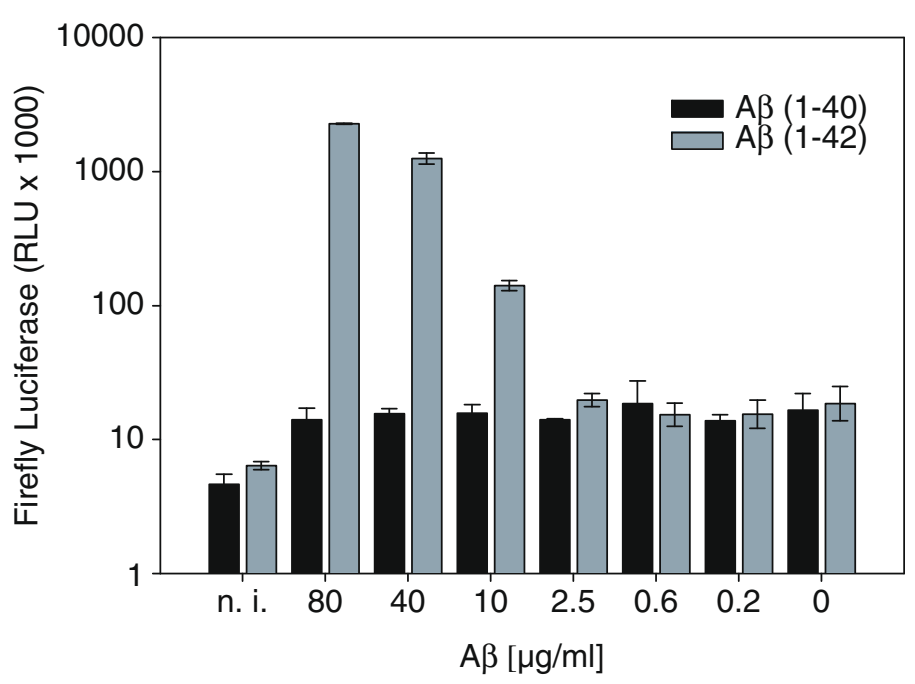

Figure $2 A \beta(1-42)$ but not $A \beta(1-40)$ fibrils enhance HIV-1 infection of TZM-bl cells. Equal amounts of the dual-tropic HIV-1 lab strain NL4-3 PI 952 [11] were pre-incubated for 5 min at RT with the indicated concentrations of $A \beta(1-42)$ or $A \beta(1-40)$ fibrils, which were incubated for four and six days, respectively of oligomerization. Subsequently, the pretreated viruses were used to infect TZM-bl reporter cells and infection-induced luciferase activity was assayed $48 \mathrm{~h}$ post infection. 
A
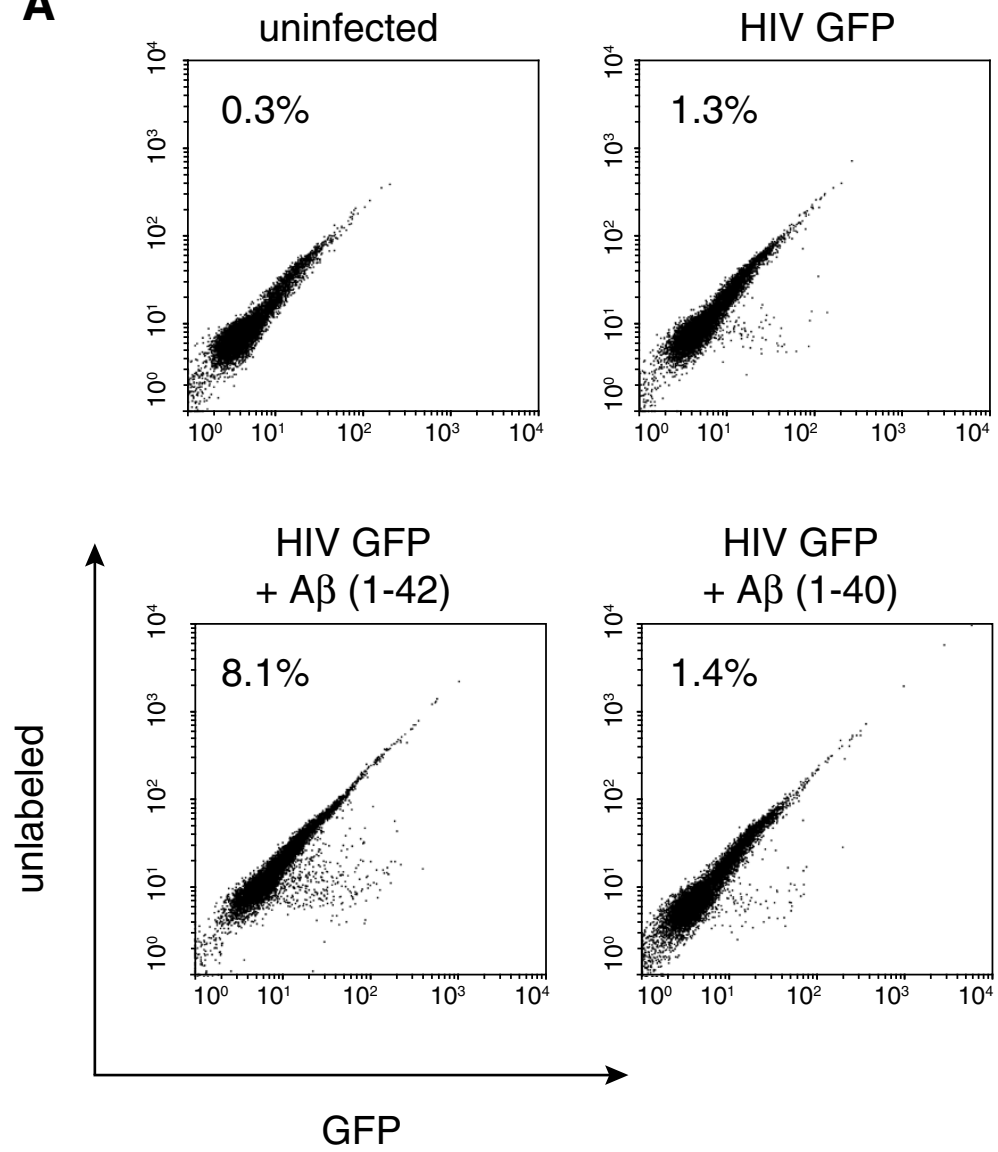

B

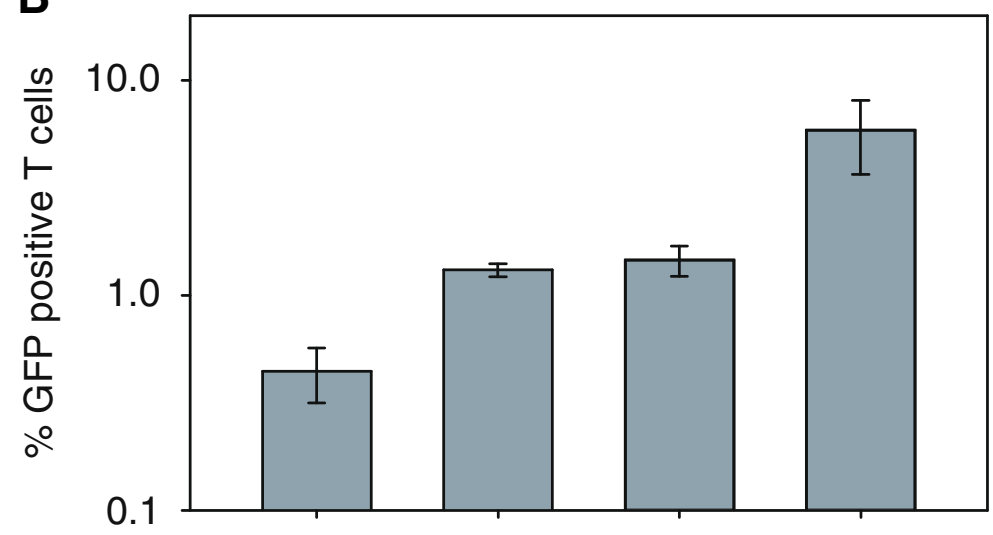

Figure $3 \mathrm{~A} \beta(\mathbf{1 - 4 2 )}$ peptide boosted infectivity of Molt-4 T cells. (A) Equal amounts of the R4 tropic HIV-1 NL4-3 lab strain expressing a NEF-GFP fusion protein were pre-incubated for $5 \mathrm{~min}$ at RT with PBS only, $A \beta(1-40)$ or $A \beta(1-42)$ fibrils $[10 \mu \mathrm{g} / \mathrm{ml}]$. Subsequently, Molt-4 T cells were infected with the pre-treated viruses and the percentage of HIV-1 infected (GFP positive) cells was assayed by FACS analysis $48 \mathrm{~h}$ post infection. (B) The percentage of HIV-1 infected (GFP positive) cells. 

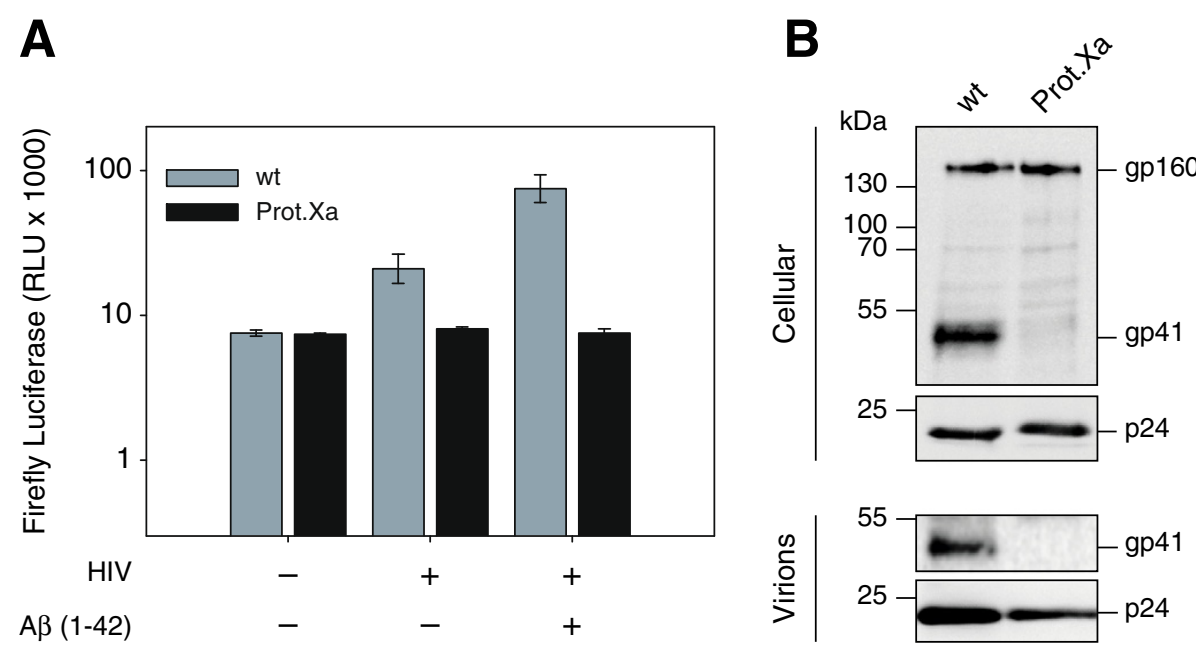

Figure 4 The fibril-mediated enhancement of HIV-1 infectivity is dependent on the membrane fusion activity of gp41. (A) TZM-bl cells were infected with R4 tropic HIV-1 strain NL4-3 (wt) or protease cleavage site mutant derivate (Prot.Xa), which were pre-incubated for 5 min at RT with $A \beta(1-42)$ fibrils $(50 \mathrm{\mu g} / \mathrm{ml})$. Infection-induced luciferase activity was assayed $48 \mathrm{~h}$ post infection. (B) Immunoblot analysis of HEK $293 \mathrm{~T}$ cells transfected with pNL4-3 or the protease cleavage site mutant pNL Prot.Xa by using Chessie 8 antibody (NIH) for gp160/gp41 analysis [15] and the p24 specific antibody (D7320, Aalto Bioreagents Ltd. Dublin, Ireland) for capsid protein detection. Virions were pelleted by using sucrose centrifugation as described before [16].

We next examined whether the peptide boosted enhancement can be reduced by pre-treatment with the noncytotoxic A $\beta$ fibril inhibitor D3 [17] (JPT; Berlin, Germany), which is a D-enantiomeric peptide (RPRTRLHTHRNR). SEVI and $A \beta(1-42)$ fibrils $(10 \mu \mathrm{g} / \mathrm{ml})$ were pre-treated with D3 and the mixture was used to boost the infection of TZM-bl cells as described above. Following an incubation time of $48 \mathrm{~h}$, the infectivity was determined by luciferase measurement and X-Gal staining (Figure 5). While SEVI and $A \beta(1-42)$ fibrils were able to boost viral infection at similar amounts, already equimolar doses of D3 $(10 \mu \mathrm{g} / \mathrm{ml})$ were sufficient to significantly reduce the enhancing effect of SEVI (Figure 5A and 5C). By adding higher amounts of D3 $(100 \mu \mathrm{g} / \mathrm{ml})$, luciferase expression was further reduced to levels comparable with PBS treated control samples (Figure 5A, 5C and 5F). Similarly, the $\mathrm{A} \beta(1-42)$ boosted infection could be reduced. By adding ten-fold higher concentration of the inhibitor D3 $(100 \mu \mathrm{g} / \mathrm{ml})$, the infection rate of $\mathrm{A} \beta(1-42)$ boosted virions was significantly reduced to levels of PBS treated viruses (Figure 5B, 5D and 5F). To further control whether the reducing effect of D3 on fibril boosted infectivity was indeed due to the fibril-D3 interaction, we also pre-incubated virus containing supernatants with D3 in the absence of fibrils and then infected TZM-bl cells. As shown in Figure 5E, when infected in the absence of fibrils the cellular luciferase activity was not affected.

HIV-1 entry in female mucosa is restricted and requires overcoming at least three hurdles. These are to breach the mucosal barrier and get through the epithelium, infection and replication in sub-epithelial mononuclear cells and the initiation of a systemic infection in the lymph nodes [18]. Since genital mononuclear cells, including dendritic cells (DCs), macrophages and lymphocytes are susceptible to HIV-1 in vivo [18], amyloid fibrils might help HIV-1 to penetrate the mucosa and to reach these cells. Thus, treatment with D3 could inhibit the first sub-epithelial contact and prevent viral spreading.

In addition to its activity to enhance the infectivity of HIV-1 in semen, amyloids could play an important role in the progression of AIDS dementia complex (ADC) also known as HIV encephalopathy, which develops in between $20 \%$ and $30 \%$ of HIV patients in the course of infection. Interestingly, the formation of $A \beta$ aggregates and fibrils is thought to precede the clinical symptoms of $\mathrm{AD}$ by three to four decades, and such fibrils may therefore be present in many midaged people. Since, the D-amino acid peptide D3 drastically reduces plaque load [17] and cognitive deficits even in orally D3 treated AD transgenic mice [10], it might be suitable to additionally reduce the fibril boosted HIV-1 infectivity in vivo.

In conclusion, the application of D3 may reduce SEVI-induced enhancement of viral infectivity of HIV1 and the vulnerability of the central nervous system of HIV infected individuals. Thus, D3 seems to be suitable as therapeutic and prophylactic drug expanding the current HIV-intervening repertoire of antiretroviral compounds. 


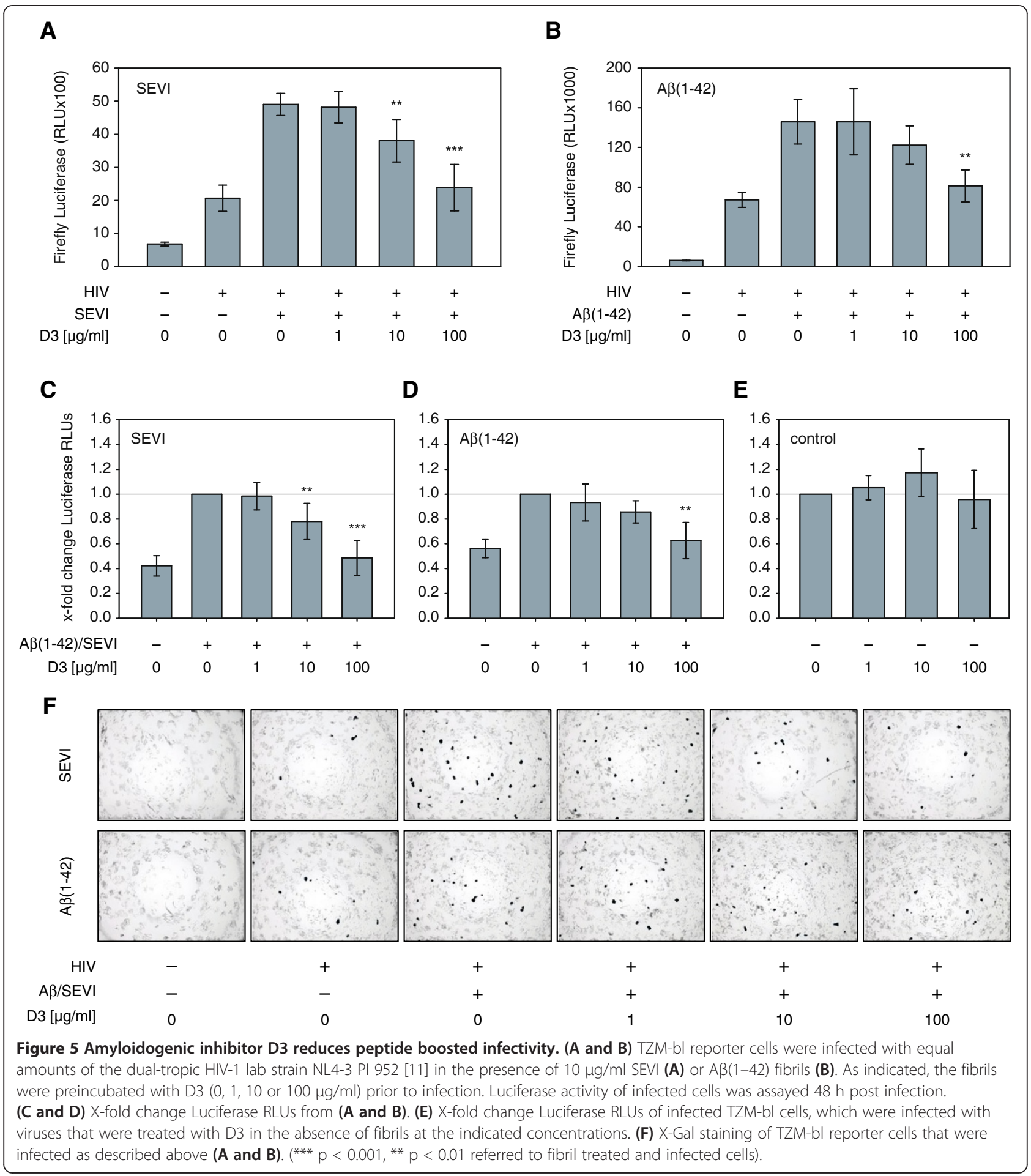




\section{Abbreviations}

Aß: Amyloid-beta; CA: Capsid; ELISA: Enzyme-linked immunosorbent assay; FACS: Fluorescence activated cell sorting; GFP: Green fluorescent protein; HIV-1: Human immunodeficiency virus type 1; PBS: Phosphate buffered saline; PLB: Passive lysis buffer; RLU: Relative light units; SEC: Size exclusion chromatography; SEVI: Semen-derived enhancer of virus infection.

\section{Competing interests}

The authors declare that we have applied for a patent related to the content of this manuscript.

\section{Authors' contributions}

MW conceived, designed, and performed HIV-related infection and readout experiments, performed the statistical analysis and drafted the manuscript. AK carried out fibril preperations. YC carried out fibril preperations. AF conceived the study, and participated in its design and coordination and helped to draft the manuscript. DW conceived the study, and participated in its design and coordination and helped to draft the manuscript. HS conceived the study, and participated in its design and coordination and helped to draft the manuscript. All authors read and approved the final manuscript.

\section{Acknowledgements}

These studies were supported, in part, by the DFG (SCHA 909/3-1), the Stiftung für AIDS-Forschung, Düsseldorf (H.S.), BMBF-Kompetenznetz Degenerative Demenzen (KNDD FKZ 01GI1010A, D.W.), DFG Graduate School 1033 (S.F., D.W.) and Jürgen Manchot Stiftung (M.W., H.S., D.W.). The following reagents were obtained through the NIH AIDS Reagent Program, Division of AIDS, NIAID, NIH: TZM-bl cells from Drs. John C. Kappes, Dr. Xiaoyun Wu and Tranzyme Inc., Chessie 8 from Dr. George Lewis [17] and Molt-4 Clone 8 from Dr. Ronald Desrosiers. We thank Dr. Michael Schreiber for providing pNL4-3 PI 952 [11] and Dr. Valerie Bosch for pNL4-3-GFP. We also thank Dr. Jan Münch for providing SEVI-fibrils.

\section{Author details}

${ }^{1}$ Institut für Virologie, Heinrich-Heine-Universität, D-40225 Düsseldorf, Germany. ${ }^{2}$ Forschungszentrum Jülich, ICS-6, 52425 Jülich, Germany. ${ }^{3}$ Institut für Physikalische Biologie, Heinrich-Heine-Universität, 40225 Düsseldorf, Germany. ${ }^{4}$ Bioanalytik, Fakultät für Angewandte Naturwissenschaften, Hochschule für Angewandte Wissenschaften Coburg, 96450 Coburg, Germany. ${ }^{5}$ Biologisch und Medizinisches Forschungszentrum (BMFZ), Heinrich-Heine-Universität Düsseldorf, Düsseldorf, Germany.

Received: 24 July 2013 Accepted: 9 January 2014

Published: 14 January 2014

\section{References}

1. Luhrs T, Ritter C, Adrian M, Riek-Loher D, Bohrmann B, Dobeli H, Schubert D, Riek R: 3D structure of Alzheimer's amyloid-beta(1-42) fibrils. Proc Natl Acad Sci USA 2005, 102:17342-17347.

2. Wojtowicz WM, Farzan M, Joyal JL, Carter K, Babcock GJ, Israel DI, Sodroski J, Mirzabekov T: Stimulation of enveloped virus infection by beta-amyloid fibrils. J Biol Chem 2002, 277:35019-35024.

3. Munch J, Rucker E, Standker L, Adermann K, Goffinet C, Schindler M, Wildum S, Chinnadurai R, Rajan D, Specht A, et al: Semen-derived amyloid fibrils drastically enhance HIV infection. Cell 2007, 131:1059-1071.

4. Roan NR, Munch J, Arhel N, Mothes W, Neidleman J, Kobayashi A, Smith-McCune K, Kirchhoff F, Greene WC: The cationic properties of SEVI underlie its ability to enhance human immunodeficiency virus infection. J Virol 2009, 83:73-80.

5. Capule CC, Brown C, Olsen JS, Dewhurst S, Yang J: Oligovalent amyloid-binding agents reduce SEVI-mediated enhancement of HIV-1 infection. J Am Chem Soc 2012, 134:905-908.

6. Olsen JS, Brown C, Capule CC, Rubinshtein M, Doran TM, Srivastava RK, Feng C, Nilsson BL, Yang J, Dewhurst S: Amyloid-binding small molecules efficiently block SEVI (semen-derived enhancer of virus infection)and semen-mediated enhancement of HIV-1 infection. J Biol Chem 2010, 285:35488-35496.

7. Hauber I, Hohenberg H, Holstermann B, Hunstein W, Hauber J: The main green tea polyphenol epigallocatechin-3-gallate counteracts semen-mediated enhancement of HIV infection. Proc Natl Acad Sci USA 2009, 106:9033-9038.

8. Sievers SA, Karanicolas J, Chang HW, Zhao A, Jiang L, Zirafi O, Stevens JT, Munch J, Baker D, Eisenberg D: Structure-based design of non-natural amino-acid inhibitors of amyloid fibril formation. Nature 2011 475:96-100.

9. Roan NR, Sowinski S, Munch J, Kirchhoff F, Greene WC: Aminoquinoline surfen inhibits the action of SEVI (semen-derived enhancer of viral infection). J Biol Chem 2010, 285:1861-1869.

10. Funke AS, van Groen T, Kadish I, Bartnik D, Nagel-Steger L, Brener O, Sehl T, Batra-Safferling R, Moriscot C, Schoehn G, et al: Oral treatment with the d-enantiomeric peptide D3 improves the pathology and behavior of Alzheimer's disease transgenic mice. ACS Chem Neurosci 2010, 1:639-648.

11. Polzer S, Dittmar MT, Schmitz H, Schreiber M: The N-linked glycan g15 within the V3 loop of the HIV-1 external glycoprotein gp120 affects coreceptor usage, cellular tropism, and neutralization. Virology 2002, 304:70-80.

12. Chien $\mathrm{P}$, Weissman JS, DePace AH: Emerging principles of conformationbased prion inheritance. Annu Rev Biochem 2004, 73:617-656.

13. Daniel MD, Li Y, Naidu YM, Durda PJ, Schmidt DK, Troup CD, Silva DP, MacKey JJ, Kestler HW 3rd, Sehgal PK, et al: Simian immunodeficiency virus from African green monkeys. J Virol 1988, 62:4123-4128.

14. Kikukawa R, Koyanagi Y, Harada S, Kobayashi N, Hatanaka M, Yamamoto N: Differential susceptibility to the acquired immunodeficiency syndrome retrovirus in cloned cells of human leukemic T-cell line Molt-4. J Virol 1986, 57:1159-1162.

15. Abacioglu YH, Fouts TR, Laman JD, Claassen E, Pincus SH, Moore JP, Roby CA, Kamin-Lewis R, Lewis GK: Epitope mapping and topology of baculovirus-expressed HIV-1 gp160 determined with a panel of murine monoclonal antibodies. AIDS Res Hum Retroviruses 1994, 10:371-381.

16. Widera $M$, Erkelenz $S$, Hillebrand $F$, Krikoni A, Widera D, Kaisers W, Deenen $R$, Gombert $M$, Dellen $R$, Pfeiffer $T$, et al: An intronic $G$ run within HIV-1 intron 2 is critical for splicing regulation of vif mRNA. J Virol 2013, 87:2707-2720.

17. van Groen T, Wiesehan K, Funke SA, Kadish I, Nagel-Steger L, Willbold D: Reduction of Alzheimer's disease amyloid plaque load in transgenic mice by D3, A D-enantiomeric peptide identified by mirror image phage display. Chem Med Chem 2008, 3:1848-1852

18. Shen R, Richter HE, Smith PD: Early HIV-1 target cells in human vaginal and ectocervical mucosa. Am J Reprod Immunol 2011, 65:261-267.

doi:10.1186/1742-6405-11-1

Cite this article as: Widera et al:: The D-amino acid peptide D3 reduces amyloid fibril boosted HIV-1 infectivity. AIDS Research and Therapy 2014 11:1.

\section{Submit your next manuscript to BioMed Central and take full advantage of:}

- Convenient online submission

- Thorough peer review

- No space constraints or color figure charges

- Immediate publication on acceptance

- Inclusion in PubMed, CAS, Scopus and Google Scholar

- Research which is freely available for redistribution 